\title{
La justificación ética y política de la punición de la instigación y la ayuda al suicidio en el ordenamiento jurídico argentino
}

José Luis Ennis

"El suicidio, lejos de negar la voluntad, la afirma enérgicamente. Pues la negación no consiste en aborrecer el dolor, sino los goces de la vida. El suicida ama la vida; lo único que pasa es que no acepta las condiciones en que se le ofrece."

A. Schopenhauer

\section{Introducción}

El objeto de este breve trabajo es reflexionar sobre los presupuestos éticos y jurídicos de la figura consagrada en el art. 83 del Código Penal argentino (en adelante CP), poniendo especial atención en su compatibilidad con los principios constitucionales que enmarcan y delimitan toda la regulación de la respuesta punitiva en nuestro ordenamiento, considerando además la posibilidad de establecer una vinculación entre aquéllos y los principios básicos de la bioética jurídica, que el mismo ordenamiento ha ido incorporando con la sanción de ciertas normas y a través de pronunciamientos judiciales de importancia.

\section{Antecedentes y regulación vigente de la instigación y ayuda al suicidio}

El art. 83 del CP establece que "Será reprimido con prisión de uno a cuatro años, el que instigare a otro al suicidio o le ayudare a cometerlo, si el suicidio se hubiese tentado o consumado." 
La disposición se ha mantenido inalterada desde la sanción del código en 1921 y existía, con matices, en los antecedentes de ese ordenamiento (Guardia 2007:501).

El Proyecto de Tejedor, de 1867, reprimía tanto a quien proveyera los medios o ayudare al suicida en la ejecución, como al propio suicida, privándolo de sus derechos civiles y anulando sus disposiciones póstumas, si el suicidio se consumaba, o sometiéndolo a una "vigilancia rigurosa" por un período de uno a tres años, si quedaba en tentativa. Seguía, de ese modo y en lo que respecta a la punición del propio suicida, al código sardo (Moreno 1923:388) y a la legislación española aplicada en el régimen colonial, en línea con las pautas del derecho canónico $^{1}$, que ya había sido criticada en este aspecto por el propio Beccaría (1978:142).

El proyecto de 1881 establecía una pena de prisión para quien prestare los medios o ayudare en la ejecución del suicidio, sin contemplar pena alguna para el propio suicida, línea seguida por los proyectos posteriores, salvo el código de 1886, que no contenía disposición alguna sobre la materia.

En el proyecto de código penal que finalmente se transformara en ley en 1921 se excluyó, como adelantáramos, la punición del suicida. Rodolfo Moreno (h) indicaba que ello se debía a la desaparición del sujeto sobre el cual podría hacerse sentir la pena, al carácter salvaje de las represiones tomadas sobre el cadáver, a la imposibilidad del suicida de defenderse y a la incidencia de las sanciones en el planto hereditario sobre terceros inocentes. En el caso del suicidio tentado señalaba que se colocaría a quien realizó un acto de desesperación en peores condiciones, sin beneficio para la sociedad (1923:385 y ss.). Con esos fundamentos se convirtió en ley la fórmula que transcribimos más arriba.

Los proyectos de reforma posteriores al Código Penal de 1921 contienen una previsión similar a la del artículo transcripto,

Hasta la sanción del Nuevo Código de Derecho Canónico de 1983, la legislación canónica prohibía expresamente que se diera sepultura eclesiástica a los suicidas (Basso 2005:116). 
a la que suman en general referencias a la posibilidad de atenuar la pena cuando existieran móviles altruistas o la expresa petición del sujeto pasivo, motivada en su intenso sufrimiento. En algunos casos se proyectó la inclusión, en el mismo apartado, de una figura de homicidio atenuado cuando mediare petición o consentimiento de la víctima y de una especial atenuación para los supuestos de suicidio común concertado (por todos, Guardia 2007:502 y ss.).

Estos antecedentes dan cuenta de la particular incidencia de la cultura occidental cristiana en la conformación de las costumbres, normas y prácticas jurídicas, de modo tal que permiten refrendar, para el ámbito local, la afirmación de J. Drane cuando indica en términos generales que "la aceptabilidad moral de la privación directa de la vida humana ha dependido bistóricamente de las creencias religiosas y las costumbres de la comunidad" (2003:36). Sin necesidad de confundir los ángulos de análisis, es necesario reconocer que el problema jurídico que involucran, en general, las decisiones al final de la vida y en particular la problemática de la instigación y ayuda al suicidio, se vincula estrechamente con la asunción de determinados presupuestos filosóficos, resultando útil la sugerencia de Dworkin (2010:9) en punto a la asunción de un posicionamiento filosófico -al menos básico- en la labor de los juristas.

Relata Drane en el trabajo citado que en las sociedades antiguas, incluso entre griegos y romanos, era considerada una práctica socialmente aceptada la liberación de los sufrimientos de quienes agonizaban, sea a través de la asistencia al suicidio como causando la muerte de quién así lo requería. Luego, con el advenimiento del cristianismo como religión oficial con Constantino, las objeciones que esta religión planteaba a cualquier tipo de decisión humana sobre el momento y la forma de morir se transformaron en moral oficial y se cristalizaron luego en normas jurídicas. Como hitos en la consolidación de esta pauta moral, destaca las posiciones de San Agustín y Santo Tomás de Aquino en contra del suicidio. Suelen resumirse en tres puntos centrales los argumentos de este último para afirmar que el 
suicidio es ilícito -en términos teológicos-: a) todo ser se ama naturalmente a sí mismo y tiende naturalmente a conservarse, siendo contrario esa tendencia natural y a la caridad por la que uno debe amarse a si mismo el acto suicida; b) el hombre es parte de una comunidad y todo lo que él es pertence a la sociedad, a la que perjudica suicidándose y c) la vida es un don dado al hombre por Dios y sujeto a su divina potestad, de modo tal que quien se suicida se apropia de una facultad que sólo a Dios pertenece (Basso 2005:348). La vigencia de esta postura es destacada por Niño con la reseña de un pasaje de la encíclica Evangelium Vitae del Papa Juan Pablo II, en el que se indica “...Dios el señor de esta vida. El hombre no puede disponer de ella.” (Niño-Sanabria 2008:353)

En un sentido más amplio, indica Núñez Paz -en el prólogo a la edición española de una obra colectiva- que en nuestra cultura occidental la implantación religiosa del carácter sagrado de la vida se basa en la creación del hombre por Dios y, por consiguiente, en una ética de raíz teológica (judía, cristiana, musulmana) que evoca el origen trascendente de la vida en cuanto a que esta ha sido sido dada por Dios al hombre -que no es su verdadero titular, sino sólo un depositario- (Dworkin et al. 2000:19).

A este origen común responde el hecho de que numerosas legislaciones, en particular las que reconocen influencia del derecho europeo continental -que receptó en su momento al derecho romano canónico-, contengan disposiciones legales que sanción la instigación y ayuda al suicidio, como ocurre con la normativa nacional transcripta más arriba.

Sin embargo, es preciso adelantar desde ahora que estimamos que en este caso la normativa jurídica -penal- no ha acompañado la modificación de la moral y las costumbres comunitarias, importando un obstáculo o velada resistencia a cambios en aquel plano que han ido consolidando una determinada concepción de la autonomía individual que amerita, a nuestro entender, una nueva discusión sobre el tema, considerando en particular si es necesario, razonable e incluso legítimo 
recurrir al uso de una sanción punitiva para reprimir determinados comportamientos en un contexto que ha registrado notables modificaciones ${ }^{2}$.

Si bien es cierto que resulta particularmente difícil encontrar pronunciamientos de condena por el delito en cuestión en la jurisprudencia nacional a lo largo del extenso período transcurrido desde la sanción del código penal y especialmente en épocas recientes, también lo es que la existencia de una previsión legal como la transcripta importa la asunción de una postura en cuestiones polémicas, con incidencia social concreta, como lo es la regulación de las prácticas eutanásicas o del suicidio asistido médicamente.

Condiciona, además, la validez de las construcciones dogmáticas del derecho penal, en la medida que no puede ser ignorada a la hora de plantear los alcances de la noción de bien jurídico -afectado o tutelado, según la postura que se asuma al respecto-, la posibilidad de considerar al consentimiento del damnificado como una causal de atipicidad o justificación, los alcances de la coacción como supuesto de inculpabilidad, la definición de la autoría por determinación, entre otras cuestiones particularmente relevantes.

\section{El artículo 19 de la Constitución Nacional, la noción de bien jurídico y el suicidio}

El artículo 19 de la Constitución Nacional (en adelante CN) establece, en su primera parte, que: "Las acciones privadas de los hombres que de ningún modo ofendan al orden y a la moral pública, ni perjudiquen a un tercero, están sólo reservadas a Dios, y exentas de la autoridad de los magistrados", consagrando de ese modo el más importante de los principios limitadores materiales o sustantivos al poder cirminalizante y a la injerencia coactiva del estado en general.

2 En el trabajo que ya hemos citado, Drane (2003:39) da cuenta del amplio debate que precedió a la modificación del régimen legal de la eutanasia y el suicidio asistido en las sociedades holanesa -primero- y belga -a continuación-. 
Así, se ha dicho que esa norma "constituye un limite infranqueable al obrar del Estado ya sea que actúe por medio de cualquiera de sus autoridades ofuncionarios o de particulares que obren por delegación, incluso por sí mismos. Ni la ley, ni la administración, ni los magistrados judiciales, ni quienes actúan por mandato de éstos pueden afectar la privacidad y la intimidad de las personas" y que implica además que no basta con sancionar leyes respetando el debido proceso adjetivo para mandar o prohibir sino que "las normas deben, además, respetar la privacidad" (Gelli 2012:1087).

Zaffaroni (2001:127) sintetiza las principales consecuencias de esta disposición para el ámbito jurídico penal señalando que: a) el estado no puede establecer una moral; b) en lugar de ello debe garantizar un ámbito de libertad moral; c) las penas no pueden recaer sobre acciones que constituyan ejercicio de esa libertad, de modo tal que "no puede haber delito que no reconozca como soporte fáctico un conflicto que afecte bienes jurídicos ajenos, entendidos como los elementos de que necesita disponer otro para autorrealizarse (ser lo que elija ser conforme a su conciencia)".

En el caso de la ayuda e instigación al suicidio es claro que, por el contenido de la norma y su ubicación en el código penal (en el Titulo I. Delitos contra las personas. Capítulo I. Delitos contra la vida), el bien jurídico involucrado no es otro que la vida del propio suicida (Donna 2008:223).

Si se acepta que el bien jurídico cuya afectación exige el principio de lesividad-que se infiere del art. 19 de la $\mathrm{CN}$ transcripto- debe ser concebido como una "relación de disponibilidad de un sujeto con un objeto" (Zaffaroni 2001:489), es necesario admitir que el consentimiento del titular del bien jurídico se impone como eximente de pena pues "no bay lesividad cuando un becho no afecta a otro por daño por peligro, ni tampoco cuando el habitante consiente ciertos cursos de acciones que pueden ser dañinos o peligrosos para el ente con el que se relaciona" (2001:499). 
Es claro que nuestra postura supone, con base en el dispositivo constitucional citado y la filosofía liberal que lo inspira, asumir que no existen bienes jurídicos indisponibles ${ }^{3}$ y que no puede el legislador no constituyente asignar ese carácter a ningún bien, incluso cuando se dispone a crear, en ejercicio de las facultades que la propia constitución le reconoce, normas penales.

Con esta base, es difícil encontrar argumentos para sostener la compatibilidad del texto del art. 83 del CP, que sanciona actos de participación -en sentido técnico estricto (Soler 1987:92)en un acto de disposición que realiza el titular indiscutido del único bien jurídico en juego, con el art. 19 de la CN. Ello así pues no puede sostenerse, sin hacer a un lado por completo al titular del bien jurídico vida involucrado en el caso, que "perjudique" a un tercero el comportamiento de quien pone un motivo para que se tome -o colabora con la ejecución- de la decisión autónoma de disponer, en el máximo grado de disposición posible que supone la destrucción o supresión completa, de un bien personalísimo como es la vida propia.

En esta línea, refiriéndose específicamente a los supuestos de suicidio asistido médicamente "en un contexto vital eutanásico", Niño y Sanabria reconocen que existe un conflicto valorativo subyacente -entre la dignidad y la autonomía, por una parte, y la inviolabilidad de la vida, por otra- mas concluyen que “...en el marco de un Estado democrático y liberal, el poder punitivo no puede ignorar la concurrencia de la voluntad dispositiva de un bien jurídico", para añadir luego que, en todo caso, es poco probable que la situación de reducción de

\footnotetext{
3 En contra, considerando a la vida humana como un bien indisponible, cita Donna (2008:224) la postura de Cerezo Mir, Mir Puig y Romero Casabona, importantes referentes del derecho penal español contemporáneo. Para estos autores la vida debe ser protegida con independencia de la voluntad del titular y la impunidad de la conducta del propio suicida no tiene nada que ver con la disponibilidad de la propia vida, sino con la eficacia de la eventual pena (Guardia 2007:506). Se opone abiertamente a esta idea de indisponibilidad Niño (2008:383).
} 
la autodeterminación del auxiliador en aquel contexto permita descartar un reproche jurídico penal ${ }^{4}$ (2008:382).

Esta incompatibilidad constitucional no existiría, claro está, en aquellas hipótesis en las que no se pone un motivo para la adopción de una decisión libre o se colabora en su ejecución, sino que se domina el hecho a través del dominio de la voluntad ajena, pues ellas constituirían un supuesto de autoría de homicidio, conforme lo dispuesto por el art. 45 del CP. Construcciones dogmáticas como las de la autoría mediata o la autoría por determinación permitirían dar una respuesta jurídico penal adecuada a todas aquellas hipótesis en las que se pudiera constatar una reducción del ámbito de autodeterminación del sujeto que se quita la vida de una entidad tal que lo llevaran a perder las riendas del suceso, conducidas por el supuesto instigador o colaborador.

\section{Lesividad y autonomía individual}

La conexión entre el principio de lesividad, como límite al ejercicio del poder punitivo estatal, y el ámbito de autonomía personal que reconoce el mismo art. 19 de la CN, surge evidente de una serie de pronunciamientos de la Corte Suprema de Justicia de la Nación, entre los que mencionaremos los casos "Bahamondez" (Fallos 316:479) y "Albarracini Nieves" (Fallos 335:799), que nos permiten establecer además una directa vinculación con el enfoque de la bioética jurídica5 ${ }^{5}$.

\footnotetext{
4 Ponen en duda estos autores la posibilidad de extender esa propuesta desincriminante a otros "contextos", aclarando que su postura no implica "una interpretación irrestricta de tal autonomía, en razón de que aquellos actos de disposición que, sin hallarse determinados por ciertos contextos circunstanciales, se orienten derechamente a la destrucción del mentado bien, carecen de legitimación por parte del orden social o legal". El razonamiento presenta, a mi entender, un salto lógico, pues conecta la falta de legitimación social con el castigo penal de determinado comportamiento, cuando ambos términos no pueden encadenarse sin una justificación más pormenorizada.

5 La serie de pronunciamientos habitualmente citada en este punto se refiere a la problemática de la tenencia de estupefacientes para consumo personal y su criminalización,
} 
En ambos casos había sido sometido a la corte federal el conflicto que generaba la negativa de un paciente perteneciente al culto de los "Testigos de Jehová" a recibir transfusiones de sangre, cuando esa práctica resultaba -en principio- necesaria para neutralizar el peligro de muerte en el que se encontraba.

Si bien en el primero de los fallos, pronunciado el 6 de abril de 1993, la mayoría de la corte consideró abstracta la cuesitón -ya que Bahamondez se había repuesto antes de que el alto tribunal se pronunciara- las consideraciones formuladas en los votos de algunos de los magistrados votantes fueron recogidas en el voto que se impuso en el segundo de los pronunciamientos, dictado el 1 de junio de 2012.

Allí se indicó, citando la disidencia de los jueces Belluscio y Petracchi en "Bahamondez", que el art. 19 de la CN "otorga al individuo un ámbito de libertad en el cual este puede adoptar libremente las decisiones fundamentales acerca de su persona, sin interferencia alguna por parte del Estado o de los particulares, en tanto dichas decisiones no violen derechos de terceros" (cons. 14).

En el considerando siguiente se cita el voto de los jueces Barra y Fayt en el mismo precedente, en el que se había indicado que la norma constitucional "concede a todos los hombres una prerrogativa según la cual pueden disponer de sus actos, de su obrar, de su propio cuerpo, de su propia vida, de cuanto les es propio. Ha ordenado la convivencia humana sobre la base de atribuir al individuo una esfera de señorío sujeta a su voluntad; y esta facultad de obrar válidamente libre de impedimentos conlleva la de reaccionar u oponerse a todo propósito, posibilidad o tentativa por enervar los límites de esa prerrogativa. En el caso, se trata del señorío a su propio cuerpo y en consecuencia, de un bien reconocido como de su pertenencia, garantizado por la declaración que contiene el art. 19 de la Constitución Nacional. La estructura sustancial de la norma constitucional

materia en la que se registra un cambiante criterio de la corte en la línea de los casos "Colavini", "Montalvo" y "Arriola" (Fallos 332:1963). 
esta dada por el hombre, que despliega su vida en acciones a través de las cuales se expresa su obrar con libertad. De este modo, vida y libertad forman la infraestructura sobre la que se fundamenta la prerrogativa constituciona1 que consagra el art. 19 de 1a Constitución Nacional".

Con base en esos antecedentes, la Corte concluyó que la posibilidad de aceptar o rechazar un tratamiento especifico hace a la autodeterminación y autonomía personal, pues los pacientes tienen derecho a hacer opciones de acuerdo con sus propios valores o puntos de vista, aun cuando parezcan irracionales o imprudentes, y que esa libre elección debe ser respetada.

También se citó el voto concurrente del juez Petracchi en el caso "Ponzetti de Balbín, Indalia c. Editorial Atlántida S. A. s/daños y perjuicios" (Fallos 306:1892), transcribiendo el pasaje en el que indicó que la base misma de la libertad moderna es "la autonomía de la conciencia y la voluntad personal, la convicción según la cual es exigencia elemental de la ética que los actos dignos de meritos se realicen fundados en la libre, incoacta creencia del sujeto en los valores que lo determinan".

En "Albarracini" se destacó además que la ley 26.529 se inscribe esa lógica, al otorgar al paciente el derecho a aceptar o rechazar determinadas terapias o procedimientos médicos "con o sin expresión de causa" (art. 2 inc. e) ${ }^{6}$.

Aún cuando está claro que los pronunciamientos reseñados se refieren a una situación que difiere, en particular en el plano de la responsabilidad penal, de la que plantea el suicidio asistido - pues la no aplicación de determinados tratamientos podría encuadrar, según el caso, en alguno de los tipos omisivos de los arts. 106, 108 del CP y no así en la figura del art. 83 del mismo

\footnotetext{
6 Tinant destaca como virtudes de esta nueva regulación, aún cuando haya configurado un marco legal de algo que de hecho venía cumpliéndose, haber instanlado el tema de la muerte y del buen morir en una sociedad que habitualmente se negaba a debatirlos y sumar una contribución para evitar que se ignore o niegue la decisión del paciente -actual o anticipada, expresada libremente- en el ámbito de la regulación de las decisiones al final de la vida (2013: 143).
} 
ordenamiento-, la aplicación de los principios invocados para resolver esta aquella situación conduce, a nuestro entender, a una solución análoga para el segundo de los supuestos.

En efecto, no puede negarse que existe una conexión entre el derecho a que sean omitidos tratamientos no deseados, el suicidio médicamente asistido y las practicas eutanásicas activas $^{7}$, pues sin necesidad de confundir cada uno de esos actos de naturaleza diversa (Drane 2003:43) podría reconocerse que aparecen como manifestaciones progresivas del reconocimiento del derecho a morir del modo que el individuo elija.

Así, si se admite que el principio de autonomía individual constituye un pilar fundamental de nuestro sistema jurídico, la punición de la colaboración de un sujeto en la adopción y/o ejecución de una decisión libre -e informada, podríamos añadir-, dispuesta en una norma de jerarquía inferior, es difícil de justificar.

Este principio de autonomía individual constituye, además, uno de los principios elementales de la bioética. Con base en la moral kantiana ${ }^{8}$ y estrechamente vinculado a la noción de

7 De hecho, la analogía de las situaciones que se dan en cada uno de estos supuestos fue la base del planteo que, invocando la cláusula de igual protección de las leyes reconocida en la Enmienda XIV de la Constitución Federal, debió tratar la Corte Suprema de los Estados Unidos en "Vacco", en el año 1997. En ese caso, la corte federal consideró que la distinción que establecían las leyes estaduales que, por una parte, permitían la interrupción de los tratamientos que sostienen la vida y por otra castigan la ayuda al suicidio -prohibiendo de ese modo la asistencia médica al suicida-, era razonable y respondía a un legítimo interés estatal en: a) resguardar la vida; b) preservar el papel del médico como el que sana a los enfermos; c) proteger a las personas vulnerables de la indiferencia, del prejuicio, de las presiones psicológicas y financieras para acabar con sus vidas. En un plano ontológico señaló además que la diferencia entre una u otra situación se sostiene en los principios jurídicos fundamentales de la intención y de la causalidad. Comentando este pronunciamiento y deteniéndose en las problemáticas que el tribunal extranjero omitió considerar, se pregunta Gelli si existe en verdad una distinción sustantiva entre ambas situaciones y afirma, recurriendo a categorías de la propia corte estadounidense, que señala Gelli que la distinción se basa, por lo menos, en una "categoría sospechosa" (1998:1346).

8 Es preciso indicar aquí que Kant trató específicamente la cuestión del suicidio, afirmando que éste "...no es lícito bajo ningún respecto, ya que representa la destrucción de la humanidad y coloca a ésta por debajo de la animalidad" (el pasaje corresponde a sus Lecciones 
dignidad, este principio está ligado a ciertos rasgos profundos que caracterizan a las personas, de modo tal que sea posible reconocer esta calidad en otro y que seamos reconocidos como tales por los demás, y podríamos recurrir a una definición sintética del mismo que indica que cada individuo tiene derecho a decidir sobre aquello que lo afecta, en particular sobre su vida y su salud (Atienza 2004:68).

En este sentido se ha dicho que la dignidad humana no es, en el ámbito de la bioética, un principio más entre otros, sino que constituye el punto de referencia decisivo para entender al actividad humana en general y todas las instituciones jurídicas, políticas y sociales (Tinat 2010:565), destacando que en el campo del derecho este principio fija límites al derecho vigente indicando cuándo la libre autodeterminación de un sujeto es éticamente legítima en un caso concreto (ídem).

Es claro, entonces, que en el análisis jurídico de cuestiones que involucran esta dimensión de la autonomía individual no pueden ser incoherentes con las coordenadas básicas que permiten enfocar los problemas bioéticos, entre ellas en particular la que indica que las personas son autónomas pues no están atadas a ningún fin, son fuente originaria de iniciativas y son responsables de sus fines, teniendo al alcance de su voluntad la libre elección de valores para el desarrollo de la vida humana (Manzini-Tinant 2008:306).

\section{El suicidio médicamente asistido como problema específico de bioética juridica}

El suicidio asistido consiste en "ayudar a morir conforme a su dignidad y sin sufrimiento a una persona lesionada o enferma no terminal con invalidez grave y permanente y dependencia total de otros, o a una persona que por su enfermedad

de ética, citadas por Atienza 2004:68). Es precisa la mención pues, con base en las nociones de dignidad y autonomía aplicadas al análisis jurídico llegaremos a una conclusión diferente sobre la "licitud" del suicidio, al menos en ese plano. 
y evolución posible se considera a si misma como una persona terminada, si lo ha pedido reiteradamente, en pleno uso de su razón y de forma libre y voluntaria" (Palacios 2009:107).

La vinculación entre el problema jurídico que venimos analizando y las prácticas médicas aparece evidente cuando se repara en la posibilidad de que la ayuda -e incluso la instigación, en este caso como recomendación técnicamente calificada que pone un motivo determinante para adoptar la decisión de concluir con la propia vida- al suicidio de una persona que cursa una enfermedad terminal o particularmente grave e incurable, puede provenir de un profesional de la medicina, que aporta con su experticia la posibilidad de reducir significativamente el sufrimiento de quien ha tomado la decisión de quitarse a la vida a través de la selección de los medios más adecuados al efecto.

Esta conexión entre ciertas prácticas médicas y problemas jurídico penales -que involucran a su vez problemas axiológicos y políticos- demuestra la plausibilidad del enfoque de la cuestión desde la bioética jurídica, entendida como aquella rama de la bioética que se ocupa de la regulación normativa y las proyecciones y aplicaciones jurídicas de la problemática bioética -las cuestiones éticas vinculadas con la medicina, las ciencias de la vida y las tecnologías conexas aplicadas a los seres humanos, y aun a todos los seres vivos y a la naturaleza-, constituyendo al mismo tiempo una reflexión crítica sobre las crecientes relaciones entre la bioética y el derecho, a escala nacional, regional e internacional (Tinant 2007:149). Específicamente, el problema del suicidio asistido sería uno de aquellos puntos en los que bioética y derecho convergen dando

9 Gherardi categoriza a los pacientes graves con riesgo de muerte según su situación clínica evolutiva, distinguiendo cuatro estados de pacientes graves: 1) crítico, con una enfermedad aguda de rápido comienzo o evento agudo en el contexto de una enfermedad crónica de curso progresivo y persistente; 2) "sin esperanzas", con una enfermedad de larga evolución pero finalmente letal; 3 ) terminal o muriente, con una enfermedad letal de plazo relativamente corto; y 4) moribundo o agonizante, cercana ya la presencia probable de la muerte (citado por Tinant 2013:123). A todas estas categorías nos referimos, en adelante, en el presente trabajo. 
el marco a una ética al final de la vida, expresada por el derecho a morir con dignidad, o a vivir con dignidad la propia muerte, involucrando así una serie de decisiones al final de la vida, que son aquellas que involucran a pacientes graves con riesgo de muerte y que pueden afectar su dignidad, así como tener un impacto significativo en la calidad, lugar y tiempo de morir (Tinant 2007:100 y 2013:125).

Aunque no sea el objeto de este estudio, podemos señalar que es posible una ética de la profesión médica que admita a la asistencia al suicidio en determinados contextos como una práctica profesional permitida, y que esta posibilidad vuelve a vincular a la cuestión ética -profesional en este caso- con lo jurídico, pues es precisamente el respeto de la autonomía individual la base de una respuesta positiva, que considere en particular el deseo de aliviar el dolor del paciente capacitado que padece una enfermedad terminal, intratable o incurable que considera incompatible con sus valores fundamentales (Dworkin 2000:27).

Drane (2003:43) destaca dos argumentos en contra del suicidio médicamente asistido: en primer lugar, alude a la preocupación por la extensión de al práctica, afirmando que "una vez que se declara el derecho a algo ese algo tiende a expandirse" incluso cuando se ponen límites a ese derecho, pues esos límites tienden a ceder a las presiones sociales e individuales; en segundo lugar, supone que "cualquier legalización del derecho al suicidio desplegará efectos sobre el conjunto de la sociedad" e incluye entre esos efectos sociales previsibles al ejercicio de presiones sobre los pacientes para que adopten la decisión de terminar con su vida. Concluye que con una legislación que autorice esta práctica "el Estado hace dejación del poder de matar en los médicos, las familias y los pacientes".

El valor de estos argumentos en una discusión seria sobre la desincriminación de la instigación y ayuda al suicidio, en particular en los casos vinculados a las prácticas médicas, es relativo. 
Por una lado, la incidencia concreta de las modificaciones legales en la "extensión" de las prácticas sociales no es una afirmación que pueda formularse sin más, sin contar con un sustento empírico suficiente. Por el contrario, al menos en nuestro ámbito, las modificaciones legales suele operar como un reconocimiento y legitimación de prácticas sociales consolidadas o particularmente extendidas -basta con mencionar aquí el reconocimiento de las uniones convivenciales, la admisión del matrimonio entre personas del mismo sexo, entre otras-.

Por otra parte, la mención de los efectos que el autor supone tendrá ese reconocimiento legal en el plano social, no constituye más que una simple conjetura. El propio autor da cuenta del debate generado en la sociedad holandesa sobre el punto y la posterior regulación de la cuestión en ese país, mas no indica que los efectos que espera hayan tenido lugar allí.

Finalmente, no se puede suscribir sin más que el Estado cuente con un legítimo "poder de matar" que no podría delegar a médicos, familiares y -paradójicamente- "pacientes" -nadie duda que estos últimos son los titulares del derecho a la vida en juego en este debate-. Por el contrario, normativa constitucional y convencional de igual jerarquía impide considerar que el estado argentino pueda administrar legítimamente el "poder de matar", afirmación que podría extenderse incluso a otros ámbitos en los que la legislación positiva admite la pena capital (Niño 2011:168 y ss), a lo que cabe agregar que no se indica por qué en una eventual disputa de poder sería más conveniente mantener la juridización extrema de la muerte que importa la existencia de sanciones penales, aplicables incluso y por falta de toda referencia expresa a quien asista médicamente a un suicida en un contexto eutanásico, frente a un temor de medicalizar el final de la vida a través de esa delegación, regresando a un biopoder médico en esas circunstancias (v. Tinant 2007:101).

Por su parte, Sissela Bok se opone a la "legalización" del suicidio médicamente asistido, y pone en cuestión su utilidad 
para el paciente y las dificultades que acarrearía, para su puesta en práctica en términos aceptables, la innegable existencia de diferencias marcadas en el acceso a las prestaciones del sistema de salud en las sociedades contemporáneas (Dworkin 2000:109 y ss.).

Estas objeciones, que podrían sumarse a las planteadas por Drane a la hora de evaluar los aspectos a tener en cuenta para regular la práctica del suicidio médicamente asistido, no dan sustento jurídico suficiente a la subsistencia de una norma penal que castiga un comportamiento que, al margen de su utilidad individual y social y de su fuerte anclaje en un marco moral religioso, no puede considerarse lesivo para un bien jurídico. Si bien es cierto que en nuestro sistema jurídico la segunda parte del art. 19 de la $\mathrm{CN}$ funciona como regla de clausura, al afirmar que todo lo que no está prohibido expresamente por la ley está permitido, pensamos que el razonamiento que supone linealmente que no castigar penalmente determinado comportamiento implica "legalizarlo" no es del todo correcto. Legalizar no es solo -o puede no ser solo- excluir un comportamiento del ámbito de lo penalmente sancionado, pues puede ser también regular determinado fenómeno social con pautas que indiquen los alcances de la actividad lícita de distintos actores frente a ese fenómeno y, en su caso, las consecuencia jurídicas -no necesariamente penales- que puede acarrear un eventual apartamiento de esas pautas.

\section{Conclusiones}

Las consideraciones expuestas hasta aquí nos permiten afirmar, con certeza, que la punición de la instigación y ayuda al suicidio no constituye exclusivamente un problema de interpretación y aplicación de la ley que pueda abordarse sin más con las limitadas herramientas de la dogmática penal. Ello así pues es claro que el tema involucra complejos problemas de compatibilidad constitucional, decisión política y justificación ética y moral, que no pueden obviarse al analizar ese puntual aspecto del régimen penal. 
En ese contexto, consideramos que el principio de autonomía individual, que encuentra concreto anclaje en la disposición del art. 19 de la $\mathrm{CN}$, permite establecer un nexo entre esos ejes de análisis y acerca una respuesta que ya insinuamos en el desarrollo del trabajo: en las decisiones individuales sobre la propia vida, incluso sobre la determinación del modo en que se pondrá fin a la misma, el Estado tiene una limitada injerencia -especialmente cuando no existen dudas sobre el carácter libre, informado y voluntario de esas decisiones- $y$, en consecuencia, el uso de las sanciones penales para limitar ciertos aspectos del ejercicio de ese ámbito de autonomía no parece plausible.

Por un lado, por razones jurídicas, de orden dogmático y constitucional, que presentan como poco razonable la punición de un comportamiento que no es más que la colaboración en una conducta de otro que no afecta a bienes jurídicos de terceros. Asumimos, desde ya, que la norma constitucional limita el uso legítimo de la criminalización a los supuestos en los que pueda reconocerse una lesión o puesta en peligro de bienes jurídicos de terceros que responde de la conducta que se conmina con una sanción penal. Por fuera de estos supuestos es posible imaginar un interés estatal legítimo para promover o desalentar determinados comportamientos, pero no puede recurrir a la última ratio que importa el uso de la violencia punitiva.

Por otra parte, el reconocimiento de la posibilidad de decidir libremente sobre el propio cuerpo, sobre el modo en que se decide vivir e incluso sobre el modo en que se decide morir, que ya encontraba anclaje jurídico en el texto constitucional, ha ido registrando paulatinos avances, a través de la legislación y la jurisprudencia, dando al principio de autonomía una nueva y más amplia dimensión incompatible, ahora sí en términos de justificación ética y política, con la subsistencia de la norma en cuestión.

En todo caso, lo hasta aquí expuesto demuestra que el tema merece un debate democrático amplio y profundo, como el que ha tenido en aquellas sociedades que han avanzado sobre el tema, despenalizando primero y "legalizando" luego el suicidio médicamente asistido. 


\section{Bibliografía}

Atienza, Manuel Bioética, Derecho y Argumentación. Bogotá: Temis, 2004.

Basso, Domingo M. Nacer y morir con dignidad. Esudios de Bioética Contemporánea. Buenos Aires: Lexis Nexis, 2005.

Baquedano, Sandra "¿Voluntad de vivir o voluntad de morir? El suicidio en Schopenhauer y Mainländer" Revista de Filosofía. Universidad de Chile 2007. Número 63, pp. 117-126.

Beccaría, César (Cesare Bonesanna, marqués de) De los delitos y de las penas. Buenos Aires: Heliasta, 1978 (1764).

Donna, Edgardo Alberto Derecho penal: parte especial. Tomo I. $3^{\text {a }}$ edición, Santa Fe: Rubinzal-Culzoni, 2008.

Dworkin, Ronald "¿Deben nuestros jueces ser filósofos? ¿Pueden ser filósofos?" Traducción de Leonardo García Jaramillo, en Isonomía Nro. 32, Abril 2010, pp. 7-29.

Dworking, Gerald; Rey, R. G. y Bok, Sissela La eutanasia y el auxilio médico al suicidio. (Traducción de Cármen Francí Ventosa) Madrid: Cambridge University Press, 2000.

Gelli, María Angélica "La prohibición del suicidio asistido. Garantía de la igualdad en una sentencia de la Corte Suprema de los Estados Unidos", en Revista La Ley, 1998-B, p. 1346.

- "La autonomía personal y los derechos de los pacientes a vivir con dignidad", en Sup. Esp. Identidad de género - Muerte digna 2012 (mayo), 93 • Revista La Ley 2012-C, p. 1087.

Guardia, Diego L. "Comentario al art. 83 del CP" en Zaffaroni, E. R. y Baigún, D. (directores) Código Penal de la Nación y normas complementarias. Análisis doctrinal y jurisprudencial. Buenos Aires: Hammurabi, 2007. Tomo III, pp. 499-521.

Manzini, Jorge L. y Tinant, Eduardo L. "Las directivas anticipadas" en Garay, Oscar (coord.) Bioética en medicina. Buenos Aires:Ad Hoc, 2008, Pp. 300-331.

Moreno, Rodolfo (h) El código penal y sus antecedentes. Tomo III. Buenos Aires: H. A. Tomassi, 1923.

Niño, Luis F. y Sanabria, Rodrigo L. "Eutanasia y suicidio asistido" en Garay, Oscar (coord.) Bioética en medicina. Buenos Aires: Ad Hoc, 2008, pp. 349-383. 
Niño, Luis F. "Acerca de la validación constitucional de las penas por parte de tribunales argentinos y estadounidenses" en Anitúa, G. I. y Yamamoto M. V. (compiladores) Pena de muerte: fundamentos teóricos para su abolición. Buenos Aires: Didot, 2011, pp. 167-188.

Palacios, Marcelo Soy mi dignidad. Eutanasia y suicidio asistido. Madrid: Libros enRed, 2009.

Soler, Sebastián Derecho Penal Argentino. Tomo 3. $4^{\mathrm{a}}$ edición, Buenos Aires: TEA, 1987.

Tinant, Eduardo L. Bioética jurídica, dignidad de la persona y derechos humanos. Buenos Aires: Dunken, 2007.

— "Luces y sombras de la llamada ley de muerte digna" en Muerte digna. Buenos Aires: La Ley, 2013, pp. 121-143.

- "Principios jurídicos y principios bioéticos. Separación, vinculación, integración" Revista Anales de la Facultad de Ciencias Jurídicas y Sociales de la Universidad Nacional de La Plata, $\mathrm{N}^{\circ}$ 40, 2010, pp. 560-572.

Zaffaroni, Eugenio R.; Alagia, Alejandro y Slokar, Alejandro Derecho Penal. Parte General. 2a edición Buenos Aires: Ediar, 2001. 